\title{
Consideraciones sobre el límite del Mar Territorial
}

\author{
por el Dr. FELIPE DE BUSTAMANTE DENEGRI
}

Ia práctica ha demostrado que no tiene razón de ser el concepto sostenido por algunos cutores del siglo pasado, de que los recursos del mar son "inagotables y suficientes para todo el mundo", ya que muchas de las especies animales que en él habitan son susceptibles de aniquilamiento si su explotación no se lleva a cabo dentro de pautas científicas determinadas. En virtud de ello, se ha venido desarrollando en el campo del Derecho Internacional una verdadera legislación sobre el particular, constituída en su primera etapa por Tratados o Convenciones bilaterales o multilaterales, $Y$, posteriormente, a partir de 1945, por Decretos o Proclamaciones de los Estados ribereños, que, siguiendo métodos diferentes (ya sea el Zócalo Continental, las Zonas de Protección y Control de las Pesquerías o la ampliación del límite de su mar territorial) tratan de reservar la primacía de la explotación a sus nacionales y de establecer un control indispensable para evitar la exterminación de las especies.

El procedimiento adoptado en la primera etapa demostró fehacientemente su ineficacia, puesto que estaba a merced de los egoísmos particu. lares de los Estados, ya que bastaba que uno de ellos, cuyos nacionales practicasen la pesca con métodos aniquiladores, rehusase participar en el sistema de acuerdos, para que la utilidad de éstos resulte gravemente comprometida y aun pueda ser nula; la disciplina y sacrificio que se imponen los contratantes sirve únicamente para asegurar a los no contratantes un beneficio ilegítimo. Como ejemplo de ello tenemos la actitud del Japón después de la sentencia del Tribunal Arbitral de París en el asunto de las focas de piel fina del Mar de Bering y el caso de las pesquerías del salmón en la Bahía de Brístol, en Alaska.

Como una reacción a la ineficacia de dicho sistema, surge la nueva tendencia iniciada por las célebres Proclamaciones del Presidente de los Estados Unidos, Harry S. Truman, de 28 de septiembre de 1945, sobre la Plataforma Continental y la determinación de Zonas de Protección de Pesquerías, que vienen a representar el esfuerzo de cada Estado para proteger las riquezas existentes en los mares adyacentes a sus costas, a fin de evi- 
tar la total destrucción de las especies y sus fatales consecuencias en la vida económica de dichos Estados.

A partir de entonces, el concepto tradicional del Mar Territorial como la parte de la superficie marítima que baña las costas de un territorio extendiéndose hasta cierta distancia de dichas costas y sobre la que los Estados ribereños ejercen plena soberanía, ha sufrido variaciones en cuanto a su amplitud, pudiéndose decir que casi el $50 \%$ de las naciones del orbe ya no aceptan el de 3 millas, límite que se originó a comienzos del siglo $\mathrm{XIX}$.

Este nuevo estado de cosas, que revela una etapa de transición del concepto tradicional, obedece a muchos motivos que lo hacen anticuada por carecer en la actualidad de base $y$ ser el Derecho Internacional un proceso en marcha que debe ir adaptándose a las nuevas necesidades y posibilidades de la humanidad.

La jurisdicción marítima en el momento de establecerse las 3 millas como limite del Mar Territorial, tenía un carácter puramente estratégico y táctico, como lo revela el hecho de haberse tomado como base el alcance máximo de un tiro de cañón de la época. Hoy en día el panorama es muy diferente, debiéndose tomar en cuenta, además del carácter de seguridad enunciado anteriormente, particularidades económicas, como muy bien la declaró Ia Corte Internacional de Justicia de La Haya con motivo de su sentencia sobre el caso de las pesquerías entre Gran Bretaña y Noruega, que permitió a este país la determinación de su Mar Territorial hasta las 4 millas, tomando como línea de base la que uniera los puntos más salientes de su litoral. De otro lado, el Tribunal Arbitral de París, en el asunto de las focas de piel fina del Mar de Bering, comprobó que el principio de la libertad de los mares era susceptible de excepciones impuestas por el interés general, del cual los Estados ribereños son los representantes más autorizados.

La humanidad entera se encuentra actualmente empeñada en el descubrimiento de nuevas fuentes de recursos de toda índole $y$ en la conservación e intensificación de las existentes, como una solución a la demanda cada vez mayor del crecimiento de la población $\mathrm{y}$ del aumento del nivel de vida ordinario. De otro lado, con los adelantos de la ciencia moderna en el campo de la técnica industrial (que permite el aprovechamiento de recursos hasta hace poco considerados como imposibles de explotación), de la aviación $\mathrm{Y}$ de los proyectiles dirigidos, ha disminuído la importancia del carácter estratégico $\mathrm{y}$ tóctico de otros tiempos.

Es interesante tener en cuenta también la situación geográfica de los países que permitirá o no la ampliación más o menos extensa del límite del Mar Territorial. Así, mientras en Europa, por encontrarse en la mayoría de los casos mares cerrados y canales más o menos estrechos, no pueden establecerse para los efectos de la pesca sino limitadas soberamías marítimas, en Ámérica los países dan frente a océanos abiertos.

Las naciones que se oponen a una renovación en este campo, son. aquellas que poseen un enorme potencial marítimo mercante e importantes: flotas pesqueras, porque en ello ven una amenaza a sus intereses, pues dicen que traería como consecuencia la destrucción del principio de la 
libertad de los mares. Lo cierto es que no existe amenaza a intereses de otros Estados ni se destruye el principio de la libertad de los mares, puesto que en los citados Decretos o Proclamaciones se reconoce a los nacionales de otros países el derecho de pesca y caza dentro del límite señalado siempre que se sometan a las reglamentaciones que sobre bases científicas se han dictado para la protección de las especies, recabando previamente el correspondiente permiso del Estado ribereño; además, se reconoce el derecho de paso inocente e inofensivo a buques de cualquiera nacionalidad, es decir, se respeta la libertad de navegación, concepto básico de la libertad de los mares. Dicho en otras palabras, de acuerdo al nuevo estado de cosas, es necesario distinguir entre la libertad de navegación y la libertad de pesca. De conformidad con la nueva tendencia, el primer principio no sufre ningún desmedro, mientras que el segundo se somete a las reglamentaciones impuestas por los Estados ribereños, a los que lógicamente debe corresponder un derecho preferencial sobre los recursos contenidos en los mares adyacentes a sus costas.

\section{EI. CASO DEL PERU}

La riqueza ictiológica existente en el mar adyacente a las costas peruanas está determinada por el plankton contenido en la Corriente Fría do Humboldt, que prócticamente las recorre en toda su extensión de Sur a Norte. Es importante también tener en cuenta que el talud continental se presenta en algunos puntos a muy escasa distancia de nuestro litoral.

Estas han sido las razones que indudablemente han tenido en cuenta nuestros legisladores para la determinación del límite de nuestro $\mathrm{Mar} \mathrm{Te}$ rritorial, el cual no toma como base el Zócalo Continental o la isobata de los 200 metros, pues entonces en algunos casos resultaría menor que el tradicional de 3 millas; ni la determinación de las Zonas de Protección y Control de Pesquerías, ya que en ese caso debería establecerse una que cubriese toda la extensión de nuestra costa basóndose en la Coniente de Humboldt.

En el caso del Perú, la conservación de sus riquezas marítimas encierra particular importancia. Aparte de constituir una fuente alimenticia de primer orden, oprovechable por la humanidad entera, viene a ser la materia prima de importantes industrias nacionales que en el caso de verse privadas de ellas, por la utilización de métodos exterminativos, producirían un fuerte desmedro en la economía nacional. Tal es el caso de nuestra floreciente industria pesquera $\mathrm{y}$ ballenera $\mathrm{y}$ el del guano de las islas, que, aparte de su importancia económica en sí, se relaciona íntimamente con la agricultura de nuestro pás, que necesita de este rico fertilizante para mantener su ritmo de producción, balanceando el déficit que se presenta en nuestros valles costeros por la falta de agua, mediante el abono continuo de las tierras que les devuelve los elementos químicos necesarios para su fertilidad. De otro lado, nuestro país, cuya producción pecutaria no alcanza a satisfacer las necesidades del consumo nacional, tiene en el pescado una fuente de proteínas que le son indispensables para la dieta alimenticia de sus habitantes. 